\title{
Linfangioma mesentérico. Raro caso clínico en Hospital de mediana complejidad en Séptima Región de Chile
}

\author{
Mesenteric lymphangioma. Rare clinical case in Hospital of medium complexity \\ in Seventh Region of Chile
}

Camila Valenzuela L. ${ }^{1}$, Raúl Valenzuela L. ${ }^{2}$, Jaime Cruz F. ${ }^{3}$,

Matías Orellana P. ${ }^{4}$, Marcelo Villarroel S. ${ }^{4}$ y Hernán Valenzuela V.

Paciente de sexo masculino de 35 años quien consulta en Hospital de Parral por aumento de volumen abdominal, constatado al examen físico.

Se solicita ecografía abdominal que evidencia extensa estructura quística multitabicada que abarca tanto cavidad abdominal como pelviana, en situación anterior a la aorta, desplazando estructuras adyacentes como hígado, bazo, riñón izquierdo y vejiga (Figuras 1,2).

Se complementa estudio con tomografía computada que confirma las características ya mencionadas en ecografía (Figura 3 ).

Se realiza laparotomía exploradora en Hospital de Linares con punción y extracción completa de

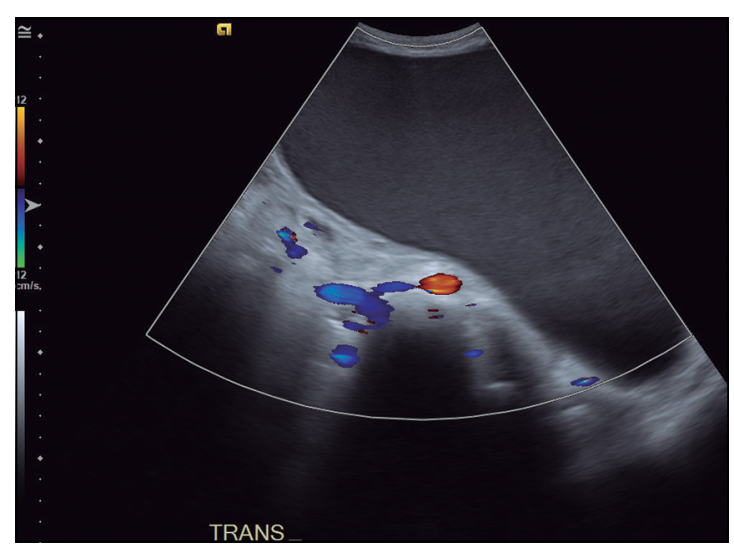

Figura 1. Ecografía de abdomen. Lesión quística en el extremo derecho de la fotografía. la lesión (Figura 4). Anatomía patológica informa linfangioma quístico mesentérico con inflamación crónica inespecífica.

Paciente evoluciona en forma satisfactoria.

Los linfangiomas son lesiones benignas de origen vascular con diferenciación linfática ${ }^{1}$.

La gran mayoría (95\%) ocurre en cabeza y cuello. El porcentaje restante se reparte en el mesenterio, retroperitoneo, vísceras abdominales y mediastino ${ }^{1}$.

Los exámenes imagenológicos (ultrasonido, tomografía computada, resonancia magnética) proveen la mejor ayuda diagnóstica para esta patología ${ }^{2}$.

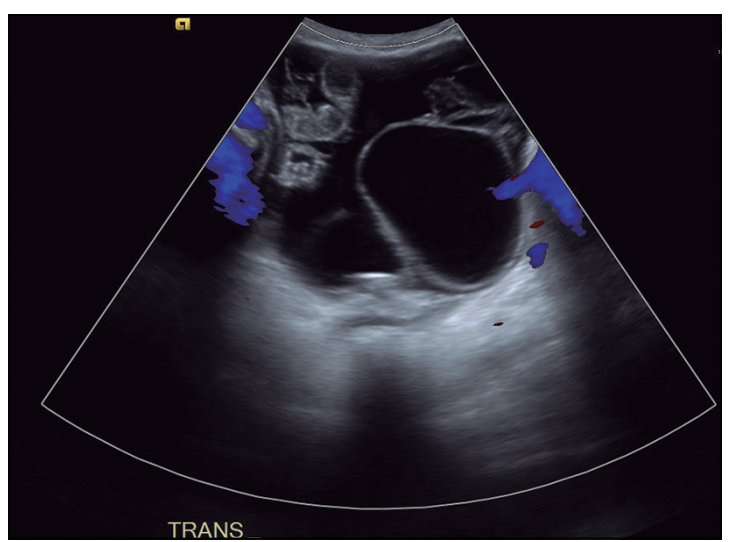

Figura 2. Ecografía de abdomen. Lesión quística a la derecha de la fotografía.
'Facultad de Enfermería. Universidad de Los Andes. Santiago, Chile.

Servicio Imagenología, Hospital de Parral. Parral, Chile.

Servicio de Medicina Interna, Hospital de Parral. Parral, Chile.

Servicio de Cirugía, Hospital de Linares. Linares, Chile. 5Servicio Imagenología Hospital de Linares. Linares, Chile.

Recibido el 12 de noviembre de 2018 y aceptado para publicación el 22 de noviembre de 2018.

\section{Correspondencia a:} Dr. Raúl Valenzuela L. ravalenzuelalabra@gmail.com 


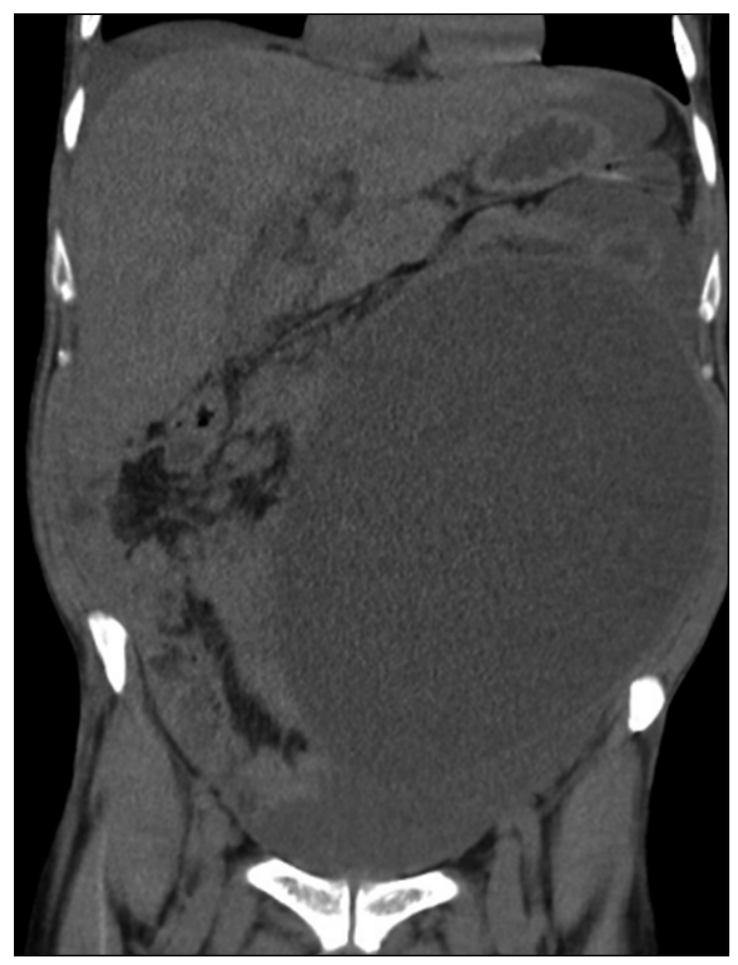

Figura 3. Tomografía computada de abdomen y pelvis, corte coronal. Lesión quística en hipocondrio, flanco y fosa iliaca izquierda.

\section{Responsabilidades éticas}

Protección de personas y animales. Los autores declaran que para esta investigación no se han realizado experimentos en seres humanos ni en animales.

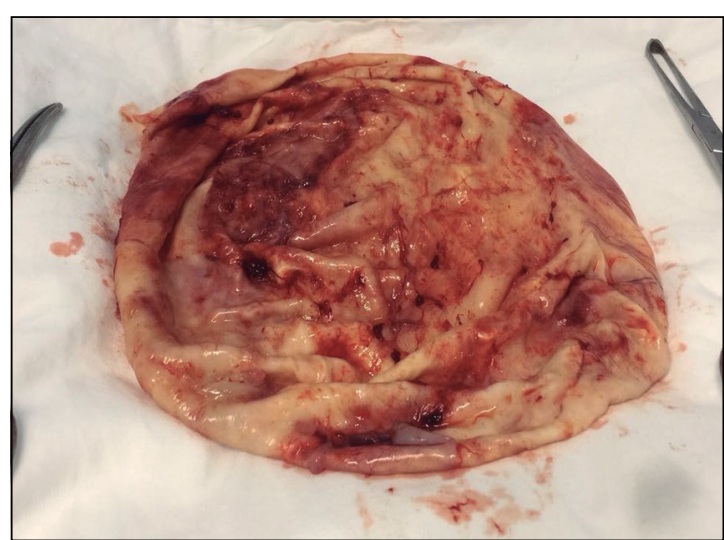

Figura 4. Aspecto macroscópico posoperatorio de quiste cuyo contenido fue aspirado.

Confidencialidad de los datos. Los autores declaran que en este artículo no aparecen datos de pacientes.

Conflictos de interés: no hay.

\section{Referencias}

1. Levy AD, Cantisani V, Miettinen M. Abdominal lymphangiomas: imaging features with pathologic correlation. AJR Am J Roentgenol. 2014;182:1485-91.

2. Reis DGD, Rabelo NN, Aratake SJ. Mesenteric Cyst: Abdominal lymphangioma. ABCD Arq Bras Cir Dig. 2014; 27:160-5. 